\title{
Status Report of Neonatal Emergencies Services in Lubumbashi (DR Congo): Case of University Clinics of Lubumbashi and of the General Hospital of Reference Jason Sendwe
}

\author{
Joelle Mabaga Mazindra1, Christian Bajima Wahelwe², Gray Kanteng', Christophe Luhata4, \\ Mutiri Muyongo Yongo ${ }^{5}$, Stanis Okitotsho Wembonyama ${ }^{3}$, Oscar Numbi Luboya ${ }^{1,3}$ \\ ${ }^{1}$ Higher Institute of Medical Techniques of Lubumbashi, Lubumbashi, Democratic Republic of Congo \\ ${ }^{2}$ Higher School of Architecture and Urbanism, Nouveaux Horizons University, Lubumbashi, Democratic Republic of Congo \\ ${ }^{3}$ Pediatric Department, University of Lubumbashi, Lubumbashi, Democratic Republic of Congo \\ ${ }^{4}$ Expanded Program on Immunization, National Directorate, Kinshasa, Democratic Republic of Congo \\ ${ }^{5}$ Far East Rand Hospital, Springs, Gauteng, South Africa \\ Email: gkanteng@yahoo.fr
}

How to cite this paper: Mazindra, J.M., Wahelwe, C.B., Kanteng, G., Luhata, C., Yongo, M.M., Wembonyama, S.O. and Luboya, O.N. (2021) Status Report of Neonatal Emergencies Services in Lubumbashi (DR Congo): Case of University Clinics of Lubumbashi and of the General Hospital of Reference Jason Sendwe. Open Access Library Journal, 8: e8148.

https://doi.org/10.4236/oalib.1108148

Received: November 3, 2021

Accepted: December 28, 2021

Published: December 31, 2021

Copyright $\odot 2021$ by author(s) and Open Access Library Inc.

This work is licensed under the Creative Commons Attribution International License (CC BY 4.0).

http://creativecommons.org/licenses/by/4.0/ (c) (i) Open Access

\begin{abstract}
Neonatal mortality is a public health problem around the world. This observation, made on a global, regional and local level, allowed us to identify in this study one of the factors that seems to interfere with the efforts of medical services to improve neonatal care in our living environment. It is about the low quality of care of the neonatal emergencies triage services as noted by an inventory of fixtures of these services in the two reference hospitals in the city of Lubumbashi: The University Clinics and the General Hospital Sendwe. The cross-sectional descriptive type is based on observation and in situ surveys, the study covered the period from 1st October 2018 to 31st March 2019, i.e., a period of 6 months. The status report touched on the following aspects: structural and physical, equipment of the services, medicines inputs, various essential materials, human resources and organization according to an external frame of reference. In the absence of local standards, we relied on recommendations concerning the establishment, the management and the use of a triage room for vital pediatric emergencies following the expert conference of French-speaking society of emergency medicine, French-speaking group of reanimation and pediatric emergency, SAMU of France, Society of anesthesia and reanimation, French-speaking reanimation society, Association of French-speaking pediatric anesthesiologists. It emerges clearly from this study the need to improve the reception frameworks over 90 years old and the structural strengthening of these triage services for vital emergencies
\end{abstract}


(RSVE) at various levels raised.

\section{Subject Areas}

Pediatrics

\section{Keywords}

Neonates, Emergencies, Mortality

\section{Introduction}

Neonatal mortality is a public health problem around the world. Levels and Trends in child mortality 2019 report show an increase in the proportion of deaths of children under 5 in the first 28 days of life, which rose from $40 \%$ in 1990 to $47 \%$ in 2018 [1].

Global neonatal mortality in the world is $18 \%$ live births with disparities. It is 7\% - 3\%o in Europe, 25\% in South Asia and 28\% in sub-Saharan Africa [1] [2]. In one order or another, the same causes of death are always reported in Africa, namely neonatal infections (13.9\% to $30.3 \%)$, asphyxia at birth (10.8\% to $50 \%)$ and complications of prematurity $(25.3 \%-42.9 \%)$ [3]-[9].

In West Africa, it is still very high. Thus, for example, we note a rate of $34 \%$ in Ivory Coast, 33\% in Mali and 36\% in Nigeria [10].

For the most part, newborns are received in health facilities in a vital emergency which immediately requires optimal care. This would require an adequate technical platform, qualified personnel, and the availability of drugs.

In the Democratic Republic of Congo, there is not a lot of literature that tackles the subject from this angle. However, in Lubumbashi, a hospital study found a frequency of neonatal death of $40.04 \%$ at the neonatology unit of the University Clinics of Lubumbashi [11].

Several factors seem to interfere with the efforts of medical services to improve neonatal care. The impact of all these factors would go through the quality of health coverage in emergency neonatal care, accessibility to care services and the qualification of nursing staff.

In our community, neonatal services in public hospitals have not grown significantly and few are those who have the minimum of a referral neonatal service.

With this study, by referring to the care of newborns in Lubumbashi hospitals, we are interested in making an inventory of features of neonatal services within the two large third-level health institutions that are the Universities Clinics and Jason Sendwe General Hospital of Reference in Lubumbashi. Our objective is to draw up an evaluation of neonatal services in the above hospitals, with attention being paid to the status report of the physical and structural infrastructure of the services, the status report of the equipment of the services, the status report of 
medicines inputs, the status report of various essential material, the status report of human resources and the status report of protocols.

It answers the question "What is the quality of neonatal care in the neonatology services of public hospitals of last resort in Lubumbashi?"

\section{Methods}

This study is of a transversal descriptive type, it covered the period from October 1, 2018 to March 31, 2019, i.e. a period of 6 months. It focused on a status report, by observing the neonatology services by focusing on the layout and operation of the neonatology services of the University Clinics of Lubumbashi and of the Provincial Reference Hospital JASON Sendwe, strictly state hospitals tertiary level. The Study Variables led to the analysis of parameters based on data related to medical infrastructure (buildings), personnel (level of training), available equipment, various inputs (drugs, etc.).

In the absence of identifiable standards in the Democratic Republic of Congo, the assessment of the state of place was made on the basis of recommendations concerning the establishment, the management and the use of a reception room of pediatric vital emergencies following the expert conference of: French-speaking emergency medicine society (FSEMS), French-speaking group for reanimation and pediatric emergency (FSGRPE), Samu of France, Society of anesthesia and reanimation (Saic), French-language reanimation society (FSRS), Association of French-speaking pediatric anesthesiologists (Afspa) [12].

Data was collected on the basis of a questionnaire developed for this purpose, tested and standardized. The collected data set was entered using Micro Soft Excel 2016 software, while analysis was performed with IBM SPSS (International Business Machine Corporation, Statistical Package for the Social Sciences) Statistics version 23 software.

\section{Results}

\section{Physical Status Report: Architecture of Buildings}

In both cases, the Neonatology Services are located in the Maternity blocks of the Hospital (Figure 1 and Figure 2).

At UCL, access is from the corridor of the Maternity ward, it is quite wide. Width $=2.95 \mathrm{~m}$. No nameplate.

Two separate rooms contain so-called non-infectious (children born in hospital) and infectious (children born elsewhere) care, each measuring approximately $11.40 \mathrm{~m}^{2}$.

At the entrance is a mother's room with 3 beds; it allows proximity to their hospitalized children $\left(14.10 \mathrm{~m}^{2}\right)$.

A space is reserved as a meeting place for doctors and trainees next to the nurses' space (the two spaces not being closed: approximately $22 \mathrm{~m}^{2}$ both);

The proximity to the operating room is immediate. 


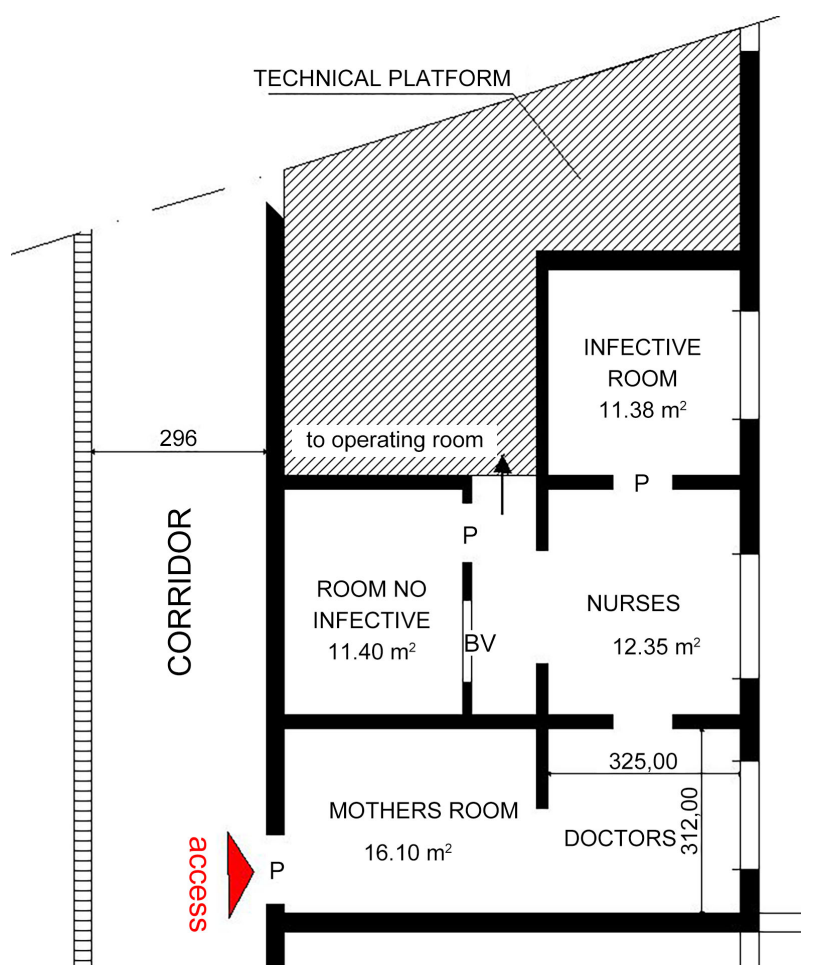

Figure 1. UCL neonatology service.

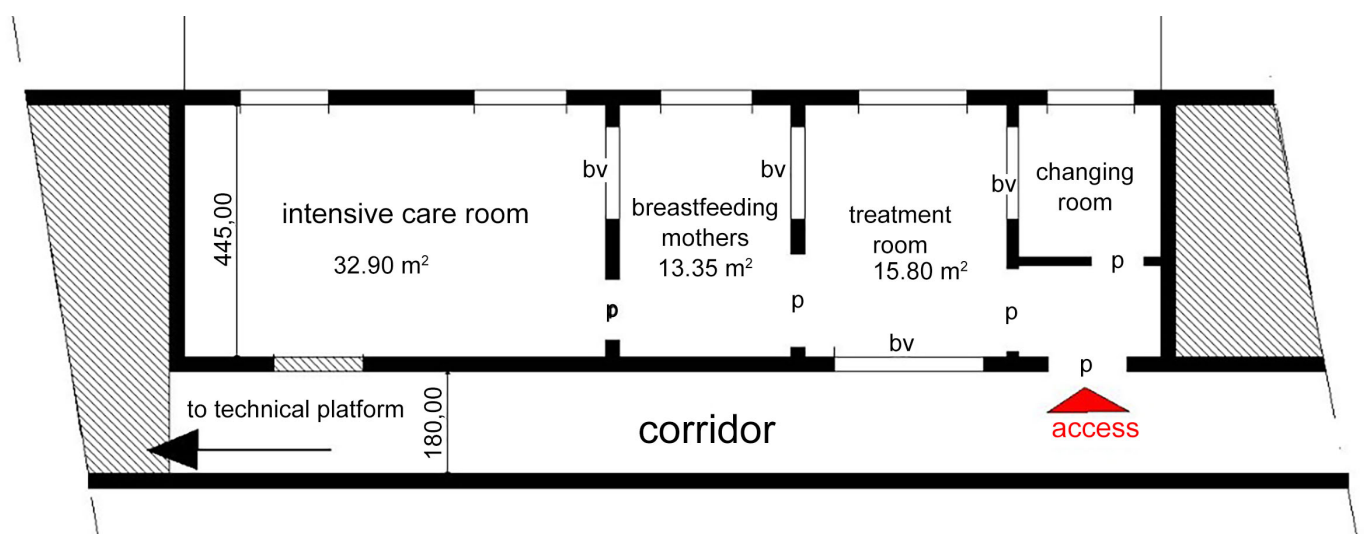

Figure 2. Neonatology service of GHR Sendwe.

There is no isolation between the reception area (mothers and doctors room) and the care area (nurses' area open to the reception area).

The size of the service is insufficient according to the reception capacity of the hospital.

The layout of the treatment rooms isolates the newborns in care from the eyes of the parents [13].

Total fitted out area $=70 \mathrm{~m}^{2}$ (for less 5 workstations).

At Sendwe, access is from the Maternity Hall, no nameplate. It is slightly wide compared to the traffic flow of all adjoining services. A separation set is possible between the reception area and the intensive care units;

Doctors and nurses are together in the so-called care space (approx. $16 \mathrm{~m}^{2}$ ); 
A single room includes the intensive care units and is only used for children born in hospital (approx. $33 \mathrm{~m}^{2}$ ). Children referred from other facilities are followed in a building elsewhere.

The development of care stations reveals promiscuity below the standard (15 $\mathrm{m}^{2}$ per location) [12].

The technical platform is too far from the Neonatology services, which is quite difficult to access (passage through the large postpartum room of the Maternity.

The size of the service is insufficient according to the triage capacity of the hospital.

Total fitted out area $=75 \mathrm{~m}^{2}$ (for 5 - 8 work stations).

From Table 1, it emerges that out of 11 indicators of the structural inventory of services, the UCL only fill in 5, while the GHR Sendwe only fill in 4 .

It emerges from this Table 2 that the indicators of the equipment of the cardiopulmonary reanimation services were insufficient in the two structures. The UCL only met 11 indicators, while the HGPR Sendwe only met 7.

In view of this Table 3, the indicators for the drug inputs were satisfactory at the CUL, while at the GHR/Sendwe the drugs were not available on site.

It appears from this Table 4 that more than $40 \%$ of the indicators of various essential materials were insufficient.

Unit staff: The number of pediatric doctors was 17 at UCL, compared to 3 at Sendwe Hospital. The number of nurses was 16 at UCL and 19 at Sendwe Hospital (Table 5).

Table 6 shows that all commonly used protocols are displayed.

Table 1. Structural status report of services.

\begin{tabular}{|c|c|c|}
\hline Indicators $[12]$ & UCL & GHR/Sendwe \\
\hline Area per location of SAUV & $80 \mathrm{~m}^{2}$ & $120 \mathrm{~m}^{2}$ \\
\hline Number of sockets for oxygen & 0 & 0 \\
\hline Number of air intakes & 0 & 0 \\
\hline Number of sockets for vacuum & 0 & 0 \\
\hline Number of sockets for electricity & 6 & 7 \\
\hline Number of infusion hooking system & 10 & 7 \\
\hline $\begin{array}{l}\text { Number of supports for monitoring devices and } \\
\text { syringe pumps }\end{array}$ & 0 & 0 \\
\hline Number of hand washing site & 3 & 2 \\
\hline Number of devices for displaying $\mathrm{x}$-rays & 0 & 0 \\
\hline Number of telephones with access to the exterior & 0 & 0 \\
\hline Number of back-up calls without leaving the room & 0 & 0 \\
\hline $\begin{array}{l}\text { Number of computers with access to the hospital } \\
\text { network }\end{array}$ & 1 & 0 \\
\hline
\end{tabular}


Table 2. Status report of the equipment of the services.

$\begin{array}{ll}\text { Indicator } & \text { UCL GHR/Sendwe }\end{array}$

\section{Respiratory reanimation}

Number of devices for the administration of medical fluids (cylinders, pressure regulators, masks, probes, nebulizers) $\quad \begin{array}{lll}5 & 2\end{array}$ and an emergency oxygen cylinder

$\begin{array}{lll}\text { Number of sets of face masks, various sizes } & 4 & 2\end{array}$

Number of sets of oropharyngeal cannulas of different sizes $\begin{array}{lll}0 & 0\end{array}$

Number of manual insufflators associated with an age-appropriate oxygen enrichment tank

$\begin{array}{ll}4 & 2 \\ 0 & 0 \\ 0 & 0 \\ 0 & 0 \\ 1 & 0 \\ 0 & 0 \\ 0 & 0 \\ 1 & 0 \\ 1 & 1 \\ 0 & 0 \\ 0 & 0\end{array}$

\section{Cardiovascular reanimation}

Number of electrocardioscopic monitors

$\begin{array}{ll}0 & 0 \\ 0 & 0 \\ 1 & 0 \\ 0 & 0 \\ 0 & 0 \\ 1 & 0 \\ 10 & 10 \\ 5 & 4 \\ 1 & 1\end{array}$

Number of automatic blood pressure measuring devices $\quad 0 \quad 0$

$\begin{array}{lll}\text { Number of manual blood pressure measuring devices } & 1 & 0\end{array}$

$\begin{array}{lll}\text { Number of defibrillators with pediatric paddles } & 0 & 0\end{array}$

Number of electrocardiogram machines $\quad \begin{array}{ll}0 & 0\end{array}$

$\begin{array}{lll}\text { Number of electric syringe pumps } & 1 & 0\end{array}$

Number of equipment for vascular and intraosseous access $\quad \begin{array}{lll}10 & 10\end{array}$

Number of transfusion kits $\quad 5 \quad 4$

Number of instantaneous hemoglobin measurement devices $\quad \begin{array}{lll}1 & 1\end{array}$

Table 3. Status report of medications inputs.

\begin{tabular}{|c|c|c|}
\hline Indicator & UCL & GHR/Sendwe \\
\hline $\begin{array}{l}\text { Presence of drugs for reanimation of respiratory, circulatory or } \\
\text { neurological failure (adrenaline, caffeine, phenobarbital, etc.) }\end{array}$ & YES & $\begin{array}{l}\text { NOT } \\
\text { AVAILABLE }\end{array}$ \\
\hline Presence of the various infusion and filling solutions & YES & $\begin{array}{l}\text { NOT } \\
\text { AVAILABLE }\end{array}$ \\
\hline $\begin{array}{l}\text { Presence of medications necessary for the management of } \\
\text { newborns and their conditions }\end{array}$ & YES & $\begin{array}{l}\text { NOT } \\
\text { AVAILABLE }\end{array}$ \\
\hline
\end{tabular}


Table 4. Status report of various essential materials.

\begin{tabular}{lll}
\hline Indicateur & UCL & GHR/Sendwe \\
\hline Number of vacuum mattresses and/or a transfer device & 0 & 0 \\
Number of reanimation stretchers & 0 & 0 \\
Number of thermometers & 5 & 3 \\
Number of incubators & 5 & 3 \\
Number of gastric tubes and recovery bags & 3 & 5 \\
Number of urinary catheters and recovery bags & 3 & 5 \\
Number of mobile imaging devices & 0 & 0 \\
Number of electronic scales & 2 & 2 \\
Number of reanimation ventilators & 0 & 0 \\
Number of invasive blood pressure measurement kits & 0 & 0 \\
Number of ultrasound-Doppler machines & 0 & 0 \\
Number of radiant tables or infrared lamps & 1 & 0 \\
\hline
\end{tabular}

Table 5. Status report of human resources.

\begin{tabular}{lll}
\hline Indicator & UCL & GHR/Sendwe \\
\hline Number of Pediatricians & 17 & 3 \\
Number of physicians in specialization & 22 & 3 \\
Number of final year medical trainees & 15 & 19 \\
Number of nurses, nursery nurses & 16 & 19 \\
Number of nurses' aides & 2 & 3 \\
\hline
\end{tabular}

Table 6. Status report of protocols.

\begin{tabular}{lll}
\hline Indicator & UCL & GHR/Sendwe \\
\hline Presence of clearly identified procedures & YES & YES \\
Presence of coordination and standardization of activities & YES & YES \\
Presence of neonatal emergency room procedures & YES & YES \\
Presence of procedures for seeking specialized advice & YES & YES \\
$\begin{array}{l}\text { Presence of a patient reception and initial management } \\
\text { structure }\end{array}$ & YES & YES \\
$\begin{array}{l}\text { Presence of protocols for the management of the most } \\
\text { frequently encountered conditions }\end{array}$ & YES & YES \\
Presence of a training of the adaptation to management & YES & YES \\
Presence of therapeutic protocols & YES & YES \\
Presence of charts and formulas for usual needs & YES & YES \\
Presence of a staff rotation list & YES & YES
\end{tabular}




\section{Discussion}

Physical status report: the minimum admissible dimensions are $15 \mathrm{~m}^{2}$ per treatment station [12]. The number of care stations in small spaces indicates overcrowding at the UCL (around $6 \mathrm{~m}^{2}$ per workstation) but are more or less acceptable in Sendwe (around $15 \mathrm{~m}^{2}$ per workstation), given the number of incubators in situ.

Aseptic conditions are not met because the rooms are permanently open and interconnected (reception area and reanimation area). It is desirable to provide mechanical ventilation to isolate the treatment rooms.

At UCL, the isolation imposed on newborns in incubators from the emotional gaze of their parents is a weakness that needs improvement. The neonatal room is an open space for babies, where everything is seen, everything is observed and everything is heard [13], think psychologists Stéphanie Huguier and Geraldine Moulin. Sendwe's only treatment room preserves this relationship somewhat, but the proximity is immediate, disturbing the distinction between the flow of caregivers and visitors.

The small dimensions of the emergency rooms limit their reception capacity because the buildings housing the Neonatology Services have been in their initial dimensions since their construction (1923 for the UCL [14] and 1928 for the GHR Sendwe [15]). These structures therefore seem outdated today given the physical and demographic growth of the city. Expansion is therefore desirable because these are reference structures, 3rd level.

Structural status report: there are obvious shortcomings here. Indeed, out of the 12 indicators proposed, the UCL have only 5 and the GHR Sendwe 4 . These units which receive newborns in an emergency panel should be equipped, for example, at least two sockets for the air, at least 3 vacuum connections; these two structures have neither [12].

The status report of the equipment of the services: this component also has shortcomings. The expert conference recommends 14 indicators for respiratory reanimation and 9 indicators for cardiac reanimation [12]. Out of the 14 proposed respiratory reanimation indicators, the UCL only fulfills 6 while the PHR Sendwe 4. As for the cardiac reanimation indicators recommended on the 9 indicators, the UCL only fulfills 5 while the GRH Sendwe 3. For Chabernaud et al. [16], Gold et al. [17] and Dehan [18], a functioning aspirator and 6, 8, 10 gauge suction tubes are among the essential equipment for reanimation of the newborn at birth.

We have listed 2 vacuum cleaners at UCL and none at GRH Sendwe. Ye et al. found 12 vacuum cleaners in the 17 centers surveyed [19]. O.-B. Tchagbeleet al had listed 15 health facilities out of the 53 visited which did not have a working vacuum cleaner [20]. This exposes newborns to breathing difficulties due to congested airways. O.-B. Tchagbele explains this lack of equipment by hardware failure or failure to replace worn out equipment [20].

F. Dicko-Traoré, et al. attribute this state of affairs rather to the problem of 
the quality of the equipment during the purchase and its renewal, to the insufficient upkeep and maintenance of the equipment [21].

Medicines inputs: note that the UCL have the minimum acceptable according to the recommendations of the expert conference; on the other hand, the GHR Sendwe does not have one [12]. For example, the UCL have medicines for the reanimation of breathing, circulatory or neurological failures, thus testifying to the organizational efforts within this institution. Indeed, these health institutions are public hospitals, they operate with a price range not to be exceeded therefore their revenue is poor. Moreover, they do not benefit from consistent support from the Congolese state. What does not allow them the satisfaction of all the indicators.

Regarding the various essential materials, the expert conference proposes 12 indicators, The UCL satisfies them at 50\%, while the GHR Sendwe only fulfills them at $40 \%$. For example, the number of incubators, the number of gastric tubes and recovery bags, the number of urinary probes and recovery bags was satisfactory; however there are no reanimation ventilators, nor reanimation stretchers.

We also find human resources and a satisfactory organization at the level of these two structures, compared to the recommendations of the conference of experts [12], which contrasts with the situation of infrastructure and equipment which turn out to be deplorable. This state of affairs is consistent with the general situation in the country marked by a lack of adequate infrastructure and medical equipment. This is also the observation of several African authors. Tchagbele during his survey on the skills of care providers working in maternity hospitals in neonatal reanimation in Togo, had listed 43 reanimation tables in the 53 health facilities [20]. Ye and his collaborators had identified two tables in the 17 centers visited in Burkina Faso, 8 embus and 12 vacuum cleaners [19].

Tchagbele had listed 15 health facilities out of the 53 visited which did not have a functional vacuum cleaner, and identified 47 functional ambushes in the 53 health facilities visited [20]. The availability of this material is often dependent in these structures on the grants received. However, the appropriation of reanimation procedures begins with the availability of adequate equipment.

On the other hand, as Chabernaud et al. [16], most medical facilities use outdated and sometimes even obsolete equipment. Therefore, it is important that a policy focused on the establishment and rational management of material resources is put in place. This will allow a full distribution of these resources between the regions and will lead to a significant improvement in the health situation of newborns throughout the territory.

\section{Conclusions}

The state of neonatal services in two tertiary level hospitals in the city of Lubumbashi: the University Clinics of Lubumbashi and the Jason Sendwe hospital enabled us to identify the following major weaknesses: 
1) The architectural structure has remained the same since their construction with the corollary of exceeding the reception capacity proportional to the demographic evolution of the city.

2) The lack of certain essential materials and equipment reduces the quality of service support.

3) The indicators identified by the various sector surveys present challenges to be taken up in order to improve the care of neonatal emergencies.

We can see the imbalance between the commitment of motivated staff and the necessary infrastructure to update according to the number of services observed.

A good policy of updating both the reception framework and international standard equipment in this area is a necessity.

There are many reasons for these difficulties, such as the quality of the nursing staff, the limited financial means, the overall inefficiency of the healthcare system, in particular. These are the levers on which decision-makers should rely in order to improve the situation of the newborn in our country if we want to achieve the 3rd objective of sustainable development, which is to reduce the death of newborns to everything at most 12 deaths per 1000 live births. The current situation emerges...

\section{Recommendations}

To state decision-makers,

1) To strengthen the hospital structures in terms of human and material resources that can allow good management of neonatal emergencies;

2) To strengthen the training of nursing staff in the care of newborns, particularly in neonatal care and reanimation of the newborn through programs such as EONC (emergency obstetric and neonatal care);

3) To promote the development of specific standards for a neonatal unit or service specific to our country, in order to be a reference tool for their implementation and their evaluations. The assistance of other actors from various disciplines such as architects, environmentalists, etc. is necessary.

\section{Conflicts of Interest}

The authors declare no conflicts of interest.

\section{References}

[1] Levels and Trends in Child Mortality Report 2019.

[2] Mejía-Guevara, I., Zuo, W.Y., Bendavid, E., Li, N. and Tuljapurkar, S. (2019) Age Distribution, Trends, and Forecasts of Under-5 Mortality in 31 Sub-Saharan African Countries: A Modeling Study. PLoS Medicine, 16, e1002757. https://doi.org/10.1371/journal.pmed.1002757

[3] Sylla, M., Folquet-Amorissani, M., Oumar, A.A., Dicko, F.T., Sidibé, T., Moyo, L., Togo, B. and Kéita, M.M. (2009) Morbidité et mortalité néonatales dans le service de réanimation pédiatrique de l'hôpital Gabriel Touré. Louvain Médical, 128, 141-144. 
[4] Azoumah, K.D., Balaka, B., Aboubakari, A.S., Matey, K., Yolou, A. and Agbèrè, A.R. (2010) Morbidité et mortalité néonatales au CHU Kara (Togo). Medecine d Afrique Noire, 57, 109-112.

[5] Bobossi Serengbe, G., Sana Deyamissi, T.S., Diemerh, C., Gaudueille, A., Gresenguet, G., Mandaba, J.L. and Siopathis, R.M. (2004) Morbidité et mortalité néonatales au complexe pédiatrique de Bangui (Centrafrique). Medecine d Afrique Noire, $51,159$.

[6] Sanou, I., Traoré, A., Kam, K.L., Yé, D., Kouéta, F., Dao, L., Zéba, B. and Sawadogo, S.A. (1998) Morbidité et mortalité néonatales au centre hospitalier universitaire Yalgado Ouédraogo de Ouagadougou (Burkina Faso) de 1993 à 1997. Burkina Médical, 2, 1822.

[7] Udo, J.J., Anah, M.U., Ochigbo, S.O., Etuk, I.S. and Ekanem, A.D. (2008) Neonatal Morbidity and Mortality in Calabar, Nigeria: A Hospital-Based Study. Nigerian Journal of Clinical Practice, 11, 285-289.

[8] Okechukwu, A.A. and Achonwa, A. (2009) Morbidity and Mortality Patterns of Admissions into the Special Care Baby Unit of University of Abuja Teaching Hospital, Gwagwalada, Nigeria. Nigerian Journal of Clinical Practice, 12, 389-394.

[9] Omoigberale, A.I., Sadoh, W.E. and Nwaneri, D.U. (2010) A 4 Year Review of Neonatal Outcome at the University of Benin Teaching Hospital, Benin City. Nigerian Journal of Clinical Practice, 13, 321-325.

[10] Geneva: World Health Organization and the United Nations Children's Fund (UNICEF) (2020) Every Newborn Progress Report (2019).

[11] Nyenga, A., et al. (2019) Trends in Neonatal Mortality in Lubumbashi (Democratic Republic of Congo) from 2011 to 2018. Clinics in Pediatrics-Pediatric Surgery, 2, Article No. 10171.

[12] Chabernaud, J.-L., et al. (2003) Recommandations concernant la mise en place, la gestion, l'utilisation et l'évaluation d'une salle d'accueil des urgences vitales pédiatriques. Réanimation, 12, 519-525. https://doi.org/10.1016/j.reaurg.2003.06.013

[13] Hugier, S. and Moulin, G. (2016) Dans l'intimité d'un service de néonatologie.

[14] Royaume de Belgique, Ministère des colonies, L'urbanisme au Congo Belge, les éditions de Visscher, sprl, 17-rue du Grand Cerf, Bruxelles, p. 132.

[15] Tshilombo Ntalaja, E. (2013) Les facteurs étiologiques de la dépression à Lubumbashi (cas de l'hôpital Sendwe et du centre neuropsychiatrique joseph-guislain): De 2009 à 2012. Université de Lubumbashi-doctorat en medicine.

[16] Chabernaud, J.L. (2005) Aspects récents de la prise en charge du nouveau-né en salle de naissance. Archives de Pédiatrie, 12, 477-490.

https://doi.org/10.1016/j.arcped.2004.09.023

[17] Gold, F., Blond, M.H., Lionnet, C. and De Montgolfier, I. (2002) Réanimation en salle de naissance. In: Gold, F., Blond, M.H. and Lionnet, C., Eds., Pédiatrie en maternité, Masson, Paris, 24-72.

[18] Dehan, M. (1993) Réanimation du nouveau-né. In: Huault, G. and Labrune, B., Eds., Pédiatrie do urgence, Flammarion, Paris, 464-466.

[19] Yé, D., Kam, K., Sanou, F., Traoré, S., et al. (2005) Prise en charge des nouveau-nés en maternité en Afrique subsaharienne: Un défi du millénaire. Archives de Pédiatrie, 12, 1275-1280. https://doi.org/10.1016/j.arcped.2005.04.082

[20] Tchagbele, O.-B., et al. (2015) Évaluation des compétences des prestataires de soins exerçant dans les maternités en matière de réanimation néonatale au Togo. Revue 
de Médecine Périnatale, 7, 245-253. https://doi.org/10.1007/s12611-015-0334-8

[21] Dicko-Traoré, F., et al. (2014) Unité de néonatologie de référence nationale du Mali. Sante Publique, 26, 115-121. 